\title{
Perceptions of the risks and benefits of Internet access and use by people with intellectual disabilities
}

\author{
D.D. Chadwick*, S. Quinn \& C. Fullwood
}

${ }^{*}$ Corresponding author

Dr. Darren D. Chadwick

Faculty of Education, Health \& Wellbeing,

University of Wolverhampton,

MC Building,

City Campus - South,

Wolverhampton, UK. WV1 1 AD

Tel: +44-(0)1902-323534

Email:d.chadwick@wlv.ac.uk

\section{Citation:}

Chadwick, D., Quinn, S. \& Fullwood, C. (2016). Perceptions of the risks and benefits of Internet access and use by people with intellectual disabilities.

British Journal of Learning Disabilities [doi:10.1111/bld.12170] 


\section{Accessible Summary}

- Both good and bad things can happen when people use the Internet and people with learning disabilities are not using the Internet as much as other people

- Worry about the bad things that can happen online might be one reason people with learning disabilities are not supported to access the Internet as much as other people

- We wanted to find out what people without learning disabilities believe about these good and bad things for people with learning disabilities.

- We wanted to find this out because the way people without disabilities think about the good and bad things online might affect how people with learning disabilities are treated.

- We found out that people without learning disabilities think that both the good and bad things are more likely to happen to people with learning disabilities when they use the Internet.

\section{Abstract}

Information and communication technologies (ICT), with the Internet at the forefront, have the potential to enhance the knowledge, service, employment, development and social interactional opportunities available to people with Intellectual disabilities. Despite this, people with intellectual disabilities are not accessing the Internet to the same degree as people without intellectual disabilities. Issues of safety, risk and protection online for people with intellectual disabilities have yet to be adequately investigated and these currently serve as reasons given for hindering people from gaining online access. This survey aimed to gauge the views people without intellectual disabilities have of risks and benefits of using the Internet for themselves and for people with intellectual disabilities and to compare self ratings of risk and benefits to ratings for people with intellectual disabilities. Results indicate that, with only a small number of exceptions, both the risks and benefits of being online were believed to be greater for people with intellectual disabilities compared with those without intellectual disabilities. Greater use of the Internet was associated with increased perception of benefits to being online for both people with intellectual disabilities and for participants. Perceptions of increased benefits suggests more needs to be done to improve online access whilst a perception of increased risk may help to explain the reduced inclusion of people with intellectual disabilities in the online world. 


\section{Introduction}

With the introduction of social media websites such as Facebook and Twitter, millions of people are now able to interact with others instantaneously over the Internet. Being online is now a central part of everyday life for many within society. However, a 'digital divide' has been found, with inequality of access to the online world between those without disabilities and those with intellectual disabilities. Hoppestad (2013) highlights how seldom people with intellectual disabilities use technology, particularly those who are adults with more severe intellectual disabilities. Chadwick et al. (2013), in a recent review, reported inequalities in Internet access with fewer opportunities available to individuals with an intellectual disability to go online. Half the respondents surveyed by Palmer et al. (2012) reported that their family member with intellectual disabilities did not have access to a computer, despite feeling that this would be beneficial for them. However, it has been reported that increasing amounts of young people with intellectual disabilities are using the Internet for learning and entertainment (Feng et al., 2008). There is some evidence suggesting that people with intellectual disabilities have much to gain from using the Internet but also may be more at risk (Chadwick \& Wesson, 2016). The perception that this group of people may be more vulnerable in experiencing risk online could lead to less support to get online and hence, to lower usage of the Internet. This may also serve to reduce the benefits of being online. However, there is a lack of literature which provides evidence of the non-disabled people's perceptions of the risks and benefits for this group of people while online. The current paper aims to address this omission.

In relation to people with intellectual disabilities, inequities continue to exist despite the potential benefits and opportunities being online can bestow. These include increased opportunities for education, communication, development, creativity and learning, participation and civic engagement, identity development and social interaction and connectedness (Bannon et al., 2015; Chadwick et al., 2012; Chadwick et al., 2013; Livingstone \& Haddon, 2009; Näslund \& Gardeklli, 2013; Stendall et al., 2011; Stendall, 2012). For example, in a sample of 172 people with disabilities, Shpigelman and Gill (2014) report that Facebook can enable people with disabilities to interact with others, helping to reduce feelings of loneliness. However, it should be noted that the majority of this sample reported having physical rather than intellectual disabilities with the majority of the sample (75.5\%) either having or working towards an academic degree. The experiences of this sample may not therefore reflect those of people with intellectual disabilities. However, in a secondary analysis of data for nine older and younger people with intellectual disabilities Näslund and Gardeklli (2013) report that, in cooperation with others, they were able to influence their levels of activity, their agency, their sense of self-esteem and self belief by using ICT. Despite some headway being made here, there remains a general lack of evidence and many of these potential opportunities and benefits remain assumed and empirically unverified for people with intellectual disabilities in the literature. 
A number of factors have been implicated in this inequity, including: financial and economic barriers; lack of policy and governmental support; lack of training and education to support people with intellectual disabilities to overcome their physical and cognitive impairments; lack of universal design, with Internet sites designed with little consideration of the needs of people with intellectual disabilities; and carers acting as gatekeepers to the Internet who may not themselves be equipped to support people into Internet use, due to their own lack of knowledge and use (Chadwick et al., 2013). This latter point is also supported by Seale (2014) who in a review on the role of supporters of people with learning disabilities, showed that one-to-one support is essential for users to gain the skills needed to engage successfully with technology. The role of the carer/supporter is therefore paramount when attempting to maximise the user's positive engagement with the Internet. However, societal and carer views of people with disability as being more vulnerable and unable to access the Internet are likely to lead to less support for people with access to the online world (Chadwick \& Wesson, 2016; Seale, 2007; Seale, 2014; Livingstone \& Haddon, 2009). As Seale, Nind and Simmons (2012) posit, perceived vulnerability, concerns over safeguarding and performance can affect the ways in those providing support think about and apply risk management ideas.

In addition to the benefits of being online there are also inherent risks, which have yet to be adequately studied in relation to people with intellectual disabilities. Generally speaking, online risks include engagement in antisocial behavior (e.g. illegal downloading, bullying, uploading sexually inappropriate pictures or text), negative contact online (e.g. having personal information stolen, being bullied, being groomed, unwelcome persuasion) and exposure to harmful, manipulative or exploitative content (e.g. advertising, violent or hateful material, harmful sexual material, extremist or racist information) (Livingstone \& Haddon, 2009). There has been little research done on the risks that people with intellectual disabilities experience online specifically. Bujis, Boot, Shugar, Fung and Bassett (2016) have recently reported briefly on some cases where individuals with intellectual disabilities have been victims of sexual harassment and financial exploitation online. Because people with intellectual disabilities are often viewed as more vulnerable, and may have someone gatekeeping their Internet access, issues of protection and control arise. The guidance and warning those with intellectual disabilities receive around online access remains unstudied. Drawing on literature focusing on physically disabled adolescents, Lathouwers et al. (2009) found that they were more likely than their non-disabled peers to be warned of the risks of the Internet by their parents and were more likely to have restrictions placed on their Internet use. Volunteer training of people with intellectual disabilities to stay safe online has been investigated in a qualitative study by Seale (2003). In this study it was apparent that those providing support took control over decisions regarding what was safe and acceptable online content for people with intellectual disabilities to access. These findings support the notion that those with intellectual disabilities are more likely to be viewed as needing protection online, although this supposition has also not yet been empirically verified. Alongside perceived vulnerability, attitudinal beliefs held by society about people with intellectual 
disabilities focusing on their deficits (Goodley, 2005; Dagnan, 2008) and viewing them as eternal children (Pueschel \& Scola, 1988) may also underpin barriers that hinder online access.

According to Adger (2006), vulnerability is the "state of susceptibility to harm from exposure to stresses associated with environmental and social change and from the absence of capacity to adapt." (p. 268). This definition puts groups lacking capacity automatically in the category of vulnerability, however it can be argued that with necessary supports people, such as those with intellectual disabilities, should not automatically be labelled as vulnerable. For these people the capacity to adapt becomes a composite of people's own resources and the support they receive, hence this capacity to adapt is mediated by the support provided or sought by an individual. Perceptions of vulnerability are predicated upon the probability of exposure to, in this case, risks in the online world. As yet this perceived likelihood has not been adequately considered in the research literature.

Although there are numerous sociological, psychological, statistical theories conceptualizing risk and vulnerability (e.g. Adger, 2006; Reyna \& Rivers, 2008; Zinn, 2006), it is beyond the scope of this paper to consider them all. However, some recent discussions in the literature have focused on the notion of 'positive risk taking' as an approach that may aid understanding and enhance online inclusion (Seale, 2014). This approach, within the context of online access, can be used to enhance wellbeing of people with intellectual disabilities through increasing opportunities for choice making in relation to the ways they wish to live their lives. Risk is not avoided, but instead acknowledged and managed and potential harm, failure or disappointment is viewed as less important than the potential for growth, self-determination and wellbeing that may occur through successful risk taking (Alaszewski \& Alaszewski 2002; Morgan 2004). A qualitative interview based study of 10 young people with intellectual disabilities and 12 staff members about their use of the Internet revealed that risk perceptions differed considerably between the two groups (Löfgren-Mårtenson, 2008). The staff were protective and worried about the risks involved in being online, underpinned by their preceptions of the young people as 'gullible'. Conversely the young people were aware of online risks but focused mainly on the risk of exclusion from the online world and how this would prevent them from being like others.

It is important to note that the exclusion, risks and benefits outlined above could apply equally to other groups, for example, Peacock and Künemund (2007) report on a sample of 16,161 European senior citizens aged 55 years and over. Of this sample only $16.8 \%$ reported using the Internet. Some of the reasons provided for non-usage related to the absence of skills and the perception that the Internet is too complicated for them to use. These findings accord with factors influencing online exclusion of those with intellectual disabilities (Chadwick \& Wesson, 2016). Moreover it cannot be assumed that the use of and gains made by people with intellectual disabilities online will necessarily be different from other groups (e.g. Seale, 2001), though this question warrants more explanation. In this study we consider whether there 
exists a perception that online experiences of risks and benefits will differ amongst non-disabled people.

Like other groups in danger of exclusion from the online world, current evidence suggests a belief that people with intellectual disabilities potentially have much to gain from engaging in online learning and social activities but also that people with intellectual disabilities may also be at more risk online. However, these beliefs have yet to be empirically verified. In addition, little is known about non-disabled perceptions of the personal risks and benefits associated with use of the Internet and how these compare to perceptions of people without intellectual disabilities. Moreover, how beliefs regarding risks and benefits relate to Internet use is as yet unstudied. The media's tendency to over-emphasise the dangers of cyberspace is likely to inform attitudes (Thurlow, 2006). A greater understanding of the non disabled people's views on this subject is a first step towards identifying potential biases, prejudices and discriminatory beliefs that members of the public may hold about Internet access to people with intellectual disabilities. These may underpin behavioural and control barriers to accessibility. To this end, this study aims to address these omissions and to the answer the following research questions:

1. What risks and benefits are perceived to be more likely to affect people with intellectual disabilities by people without intellectual disabilities?

2. How do the perceived risks and benefits for people with intellectual disabilities of being online compare with self ratings for the risks and benefits perceived for people without intellectual disabilities?

3. How does Internet use relate to perceptions of online risks and benefits both for oneself and people with intellectual disabilities? 


\section{Method}

\section{Survey Design}

This quantitative study employed a descriptive survey to gather data regarding Internet use and self ratings and ratings for people with intellectual disabilities about the risks and benefits of being online. Demographic and background information was also gathered in the survey and are reported in Table 1. The remainder of the survey contained closed questions relating to Internet use and perceptions of the risks and benefits of being online. There was no external funder for this research study.

\section{Internet use}

Participants were asked to indicate how often they used the Internet for 11 different activities (e.g. Social Networking, Blogging). Responses were given on a 6-point Likert scale ranging from 'Never' (scored 1) to 'Every day' (scored 6 ). The responses from these 11 activities were averaged to provide a score of 'internet use'. The scale had good internal reliability, Cronbach's alpha = 69 .

\section{Perceptions of risks and benefits}

The list of potential risks and benefits were adapted from Livingstone and Haddon (2009). Adaptations included ensuring that the questions were appropriate to adults and incorporation of questions more relevant to people with intellectual disabilities (e.g. opportunity to engage with online advocacy groups). Participants were provided with a list of 24 potential risks (e.g. being bullied or harassed) and asked to indicate the degree to which they perceived each to be a risk to themselves and the degree to which they perceived each to be a risk to people with intellectual disabilities. Responses regarding the likelihood of the risk occurring were given on a 5 point Likert scale ranging from 'No Risk (scored 1) to 'Very high risk' (scored 5). Responses were averaged to provide a mean scored of the self ratings of potential risks to the participant and a mean score of ratings of potential risks to people with intellectual disabilities. The scale was found to be internally reliable, Cronbach's alphas $=.94$ for both perceptions of risk.

Participants were also provided with a list of 28 potential benefits and asked to respond in the same way as described above ('No benefit', scored 1; 'Very high benefit' scored 5). As with the perception of potential risks, a mean score was calculated for the participant self ratings and for ratings of people with intellectual disabilities. Both benefit scales were found to be internally reliable, (Cronbach alphas $=.95$ for the participant self ratings and .94 for perceptions of people with intellectual disabilities).

\section{Participants}


An opportunity sample of 166 members of the general population (78.9\% Female, $\mathrm{N}=131$; Mean age $=25.35, \mathrm{SD}=10.39$ ) who did not have intellectual disabilities was recruited into the study via an advertisement circulated via local and national email distribution lists, online forums and public notice boards. The majority of the sample described themselves as either British, dual heritage or European (Table 1) with the others reporting that they are Black, Indian, Pakistani, Bengali, Asian and mixed race. The majority of participants had post-school qualifications.

Diversity was evident in the extent to which people reported coming into contact with people with intellectual disabilities, with around one third of participants coming into contact with people with intellectual disabilities regularly $(34.1 \%, N=57), 15.1 \%(N=25)$ having monthly contact and half of the participants $(50 \%, N=83)$ seldom coming into contact with people with intellectual disabilities. A number of respondents were parents $(22.9 \%, \mathrm{~N}=38)$ and many participant households had children living in them $(39.2 \%, \mathrm{~N}=65)$. The mean number of people living in respondent households was 3.87 $(S D=1.53)$.

Table 1: Participant demographic and background characteristics

\begin{tabular}{|l|r|r|}
\hline Variable & N & $\%$ \\
\hline Self defined nationality/ethnicity (N=149) & & \\
\hline White British, Dual heritage or European & 102 & 68.5 \\
\hline Black & 8 & 5.4 \\
\hline Indian & 17 & 11.4 \\
\hline Pakistani & 5 & 3.4 \\
\hline Bengali & 1 & 0.7 \\
\hline Asian & 6 & 4.0 \\
\hline Mixed race & 10 & 6.7 \\
\hline & & \\
\hline Education (N=153) & & \\
\hline Left school at 16 years or younger & 3 & 2.0 \\
\hline Post school higher qualification (e.g. A level, Diploma etc.) & 127 & 76.5 \\
\hline Degree level Education & 9 & 5.4 \\
\hline Postgraduate qualification (e.g. MSc. PhD etc.) & 14 & 8.4 \\
\hline Contact with People with LD (N=165) & & \\
\hline Regular (>Monthly) & & \\
\hline Monthly & 57 & 34.1 \\
\hline Seldom (<Monthly) & 25 & 15.1 \\
\hline Household Composition \& Roles (N=166) & 83 & 50.0 \\
\hline Parent & & \\
\hline Children living in participant household & & \\
\hline & 38 & 22.9 \\
\hline Mean number of people living in respondent household & 65 & 39.2 \\
\hline & & \\
\hline & $\mathbf{M}$ & $\mathbf{S D}$ \\
\hline & & 1.53 \\
\hline
\end{tabular}

It is unknown whether the sample recruited here is representative of the wider general population though it may be unlikely given that one third or participants regularly come into contact with people with intellectual 
disabilities (see Table 1) and that one of the email distribution lists and the notice boards used to advertise the study were geographically local to the authors based in the North East and West Midlands of England.

Nevertheless, the primary focus of the study was to provide a comparison of self-ratings to ratings of people with intellectual disabilities.

\section{Procedure}

Ethical approval was gained for the study from the University of Wolverhampton, Faculty of Education, Health and Wellbeing ethics committee. Prior to completing the survey ${ }^{1}$, an information sheet and consent form were completed. Participants were given the option of completing the survey either online ( $\mathrm{N}=129)$, by using the link provided in the advertisement, or on paper via the post $(\mathrm{N}=37)$. For the latter, on seeing the advertisement to participate in the study, participants could contact the authors for a copy of the survey to complete and return via prepaid envelope. Using the two methods of data collection was done in order to reduce the likelihood that the study would become biased towards people who were online, who, as a result, may be more accepting and predisposed to see the benefits of using the Internet (Porter \& Donthu, 2006). A de-brief sheet was made available to participants on completion of the survey this information was available at the end of the online survey or was given, emailed or posted to participants depending upon their preferred method and the way they returned the paper copy.

\footnotetext{
${ }^{1}$ Copies of the data collection materials used in this study are available upon request from the first author.
} 


\section{Results}

\section{Perceived online risks for people with intellectual disabilities}

The greatest perceived risks of being online for people with intellectual disabilities were being bullied, threatened or harassed online, providing too much personal information to others and being susceptible to online marketing scams. As can be seen in Table 1, many other online activities were also considered high risk for people with intellectual disabilities.

Comparing these to the self-ratings of the people without intellectual disabilities, different risks were perceived as more likely to affect the participants themselves, including being exposed to inappropriate or offensive adult pornographic content, becoming addicted to using social networking sites, spending less time on work, learning or personal development, engaging in copyright infringement and illegal downloading and being hacked. Inadvertently downloading spyware or malware (e.g. viruses) onto one's computer was viewed as a high risk for both groups, though higher for those with intellectual disabilities. Respondents rated few risks as high for themselves. Notably, some of the risks perceived as highest for respondents themselves were rated as more highly risky, though not most risky, for people with intellectual disabilities.

The risks rated as least likely for both people with intellectual disabilities and respondents were the arguably anti-social behaviours of bullying others online, writing harmful online content and using online gambling sites. Being stalked and having physical health be affected by spending too much time on social networking sites were also rated as some of the least likely risks for people with intellectual disabilities. For personal ratings being 'groomed' for sexual exploitation or abuse and being susceptible to online marketing scams were the other risks rated as least likely.

\section{Perceived risks of being online: Comparing self ratings and ratings for people with intellectual disabilities}

Analysis using a repeated measures MANOVA revealed a main effect for group rated, with ratings of risk being higher for people with intellectual disabilities compared with self ratings $(F(1,156)=234.73, p<.001$; Partial $\left.E_{T A}{ }^{2}=.60\right)$. To follow a series of paired sample t-tests on the individual risk items were conducted, employing the Bonferonni correction, which gave an alpha value of $p<.002$. All online risks were perceived to be significantly greater for people with intellectual disabilities ( $p<.001$ all comparisons). This pattern of findings held for the overall risk scale with significant higher risk ratings for people with intellectual disabilities $(\mathrm{t}(156)=15.32, p<.001$; intellectual disabilities Risk Mean $=3.25(\mathrm{SD}=.64)$ \& Personal Risk Mean $=$ $2.35(\mathrm{SD}=.70)$. 


\section{Perceived online benefits and opportunities for people with intellectual disabilities}

For people with intellectual disabilities, social and support related online activities were viewed as most beneficial, comprising the social opportunities to engage with social groups and maintain friendships and the support opportunities to participate in support groups and access and use advice sites (e.g. those pertaining to benefits, health, relationships etc.)

Online developmental opportunities were viewed as most beneficial in selfratings, these included finding out and being inspired to try new things and finding out about educational and work opportunities (e.g. college courses). The latter of which was one of only two opportunities rated by respondents as one of the greatest benefits for both themselves and for people with intellectual disabilities. The other shared benefit was the social opportunity to keep in contact with friends and family online. A final benefit rated as highly beneficial for respondents was the supportive role of being there to help support friends. Notably, some of the benefits perceived as highest for respondents themselves were rated as more highly beneficial, though not the most beneficial aspects of being online for people with intellectual disabilities.

The majority of respondents rated all of the potential online opportunities as highly likely to be beneficial for people with intellectual disabilities. However, the aspects viewed as least likely to be beneficial were that people with intellectual disabilities could say things they would find uncomfortable saying face to face online, develop perspective taking, decision making and critical thinking skills, and gain a sense of who they are. This latter benefit being one of the lowest contradicts the literature reporting benefits to identify formation online (e.g. Bannon et al., 2015; Chadwick et al., 2012). The benefits that more typically aligned with the lives of people with intellectual disabilities were rated as some of the least beneficial for participants themselves (i.e. the Internet giving opportunities to participate in support and advocacy groups), sharing information about their lives with others and developing social and decision making skills were the other benefits of Internet use rated least likely. The latter of which was the only overlap in the benefits viewed as one of the least likely for both of the two groups.

\section{Perceived online opportunities and benefits: Comparing self ratings and ratings for people with intellectual disabilities?}

Analysis using a repeated measures MANOVA revealed a main effect for group rated, with ratings of benefits being higher for people with intellectual disabilities compared with self ratings $(F(1,157)=75.08, p<.001$; Partial $\mathrm{ETA}^{2}=.32$ ). Subsequently, a series of paired sample t-tests on the individual benefit items were carried out, employing the Bonferonni correction, which once again gave an alpha value of $p<.002$. The t-tests revealed that the majority of the online benefits and opportunities were rated as significantly more beneficial for people with intellectual disabilities $(p<.001)$ (see Table 2). The exceptions were, keeping in contact with friends and family $(p=.10)$, 
sharing advice $(p=.10)$ and supporting friends $(p=.26)$ and learning about other cultures $(p=.35)$, work $(p=.94)$, educational opportunities $(p=.42)$ and helping to develop critical thinking skills $(p=.45)$. One other exception was the benefit of online opportunity to learn about and be inspired to try new things, where the self ratings indicated that this benefit was viewed as greater for those without intellectual disabilities $(p<.001)$. In line with the majority of item comparisons and the MANOVA result, comparison of the overall benefits/opportunities scale scores indicated significantly greater perceptions of online benefits reported for people with intellectual disabilities $(\mathrm{t}(158)=$ 8.67, $\mathrm{p}<.001$; intellectual disabilities Benefit Mean $=3.64(\mathrm{SD}=.60)$ \& Personal Benefit Mean $=3.28(S D=.67)$.

\section{The relationship between the perceived risks and benefits of Internet use and self-reported Internet use}

Correlating the self reported Internet use scale revealed that greater Internet use by participants correlated positively with higher perceived benefits of Internet use for both the participants themselves $(r(144)=.20, p=.02)$ and for people with intellectual disabilities $(r(148)=.18, p=.03)$. Internet use did not correlate significantly with perceived risk for either group ( $p>.05)$.

Looking at the individual online activities, use of social networking sites, general web browsing and shopping were the three online activities most strongly related to a belief in online benefits (intellectual disabilities:

$r(161)=.22, p=0.005 ; r(160)=.0 .16, p=.045 ; r(159)=0.16, p=.049$, respectively. Personal: $r(157)=0.31, p<0.001 ; r(156)=.0 .20, p=.01 ; r(155)=0.17, p=.04$, respectively). Use of social networking sites was the only online activity which significantly correlated with online risk ratings for people with intellectual disabilities $(r(159)=.18, p=.02)$ and for the respondents themselves $(r(158)=.23, p=.01)$.

\section{The relationship between the perceived risks and benefits of Internet use and background characteristics}

Surprisingly, regularity of contact with people with intellectual disabilities did not correlate with the perceived risks or benefits of being online for people with intellectual disabilities or others $(p>.05)$. Having children in the household positively correlated with perceived benefit to being online for people with intellectual disabilities $(r(160)=.19, p=.02)$. Female respondents were also more likely to perceive greater online risk for themselves when compared with male respondents $(t(156)=-2.0, p=.049)$. 
Table 2: Showing the mean risk ratings for online risks for people with LD and participants and the proportion of participants rating the risks as low, moderate or high for the two groups

\begin{tabular}{|c|c|c|c|c|c|c|c|c|c|c|c|c|c|c|c|c|}
\hline \multirow{3}{*}{ Risks } & \multicolumn{8}{|c|}{ People with Intellectual Disabilities } & \multicolumn{8}{|c|}{ Personal Ratings (People without ID) } \\
\hline & \multirow[t]{2}{*}{$\mathbf{M}$} & \multirow[t]{2}{*}{ SD } & \multicolumn{2}{|c|}{ Low } & \multicolumn{2}{|c|}{ Mod. } & \multicolumn{2}{|c|}{ High } & \multirow[t]{2}{*}{$\mathbf{M}$} & \multirow[t]{2}{*}{ SD } & \multicolumn{2}{|c|}{ Low } & \multicolumn{2}{|c|}{ Mod. } & \multicolumn{2}{|c|}{ High } \\
\hline & & & $\mathrm{N}$ & $\%$ & $\mathrm{~N}$ & $\%$ & $\mathrm{~N}$ & $\%$ & & & $\mathrm{~N}$ & $\%$ & $\mathrm{~N}$ & $\%$ & $\mathrm{~N}$ & $\%$ \\
\hline Being bullied or harassed & 3.68 & 0.89 & 14 & 8.4 & 46 & 27.7 & 104 & 62.7 & 2.29 & 0.87 & 107 & 64.5 & 43 & 25.9 & 11 & 6.6 \\
\hline $\begin{array}{l}\text { Communicating with people not known to them or } \\
\text { their families }\end{array}$ & 3.51 & 0.92 & 18 & 10.8 & 59 & 35.5 & 87 & 52.4 & 2.39 & 1.04 & 96 & 57.9 & 44 & 26.5 & 23 & 13.8 \\
\hline $\begin{array}{l}\text { Being exposed to inappropriate or offensive adult } \\
\text { pornographic content }\end{array}$ & 3.35 & 1.04 & 27 & 16.2 & 65 & 39.2 & 72 & 43.4 & 2.46 & 1.18 & 93 & 56.0 & 38 & 22.9 & 32 & 19.3 \\
\hline $\begin{array}{l}\text { Being exposed to inappropriate material relating to } \\
\text { drugs }\end{array}$ & 3.08 & 1.10 & 54 & 32.5 & 51 & 30.7 & 59 & 35.5 & 2.39 & 1.18 & 95 & 57.2 & 38 & 22.9 & 30 & 18.0 \\
\hline $\begin{array}{l}\text { Being exposed to material which encourages anti- } \\
\text { social or extremist behaviour }\end{array}$ & 3.02 & 1.06 & 50 & 30.1 & 62 & 37.3 & 52 & 31.3 & 2.36 & 1.05 & 95 & 56.2 & 45 & 27.1 & 23 & 13.8 \\
\hline Providing too much personal information & 3.83 & 0.99 & 14 & 8.4 & 40 & 24.1 & 110 & 66.3 & 2.25 & 1.02 & 107 & 64.5 & 36 & 21.7 & 20 & 12.0 \\
\hline $\begin{array}{l}\text { Meeting up with someone offline who they have } \\
\text { made friends with online }\end{array}$ & 3.45 & 1.11 & 33 & 19.9 & 46 & 27.7 & 84 & 50.6 & 2.21 & 1.16 & 105 & 63.2 & 33 & 19.9 & 25 & 15.0 \\
\hline Being threatened & 3.57 & 0.97 & 23 & 13.8 & 49 & 29.5 & 92 & 55.5 & 2.48 & 0.96 & 90 & 54.3 & 50 & 30.1 & 24 & 14.4 \\
\hline Missing out on face to face interactions & 3.31 & 1.05 & 35 & 21.1 & 49 & 29.5 & 79 & 47.5 & 2.26 & 1.13 & 105 & 63.2 & 32 & 19.3 & 26 & 15.6 \\
\hline $\begin{array}{l}\text { Affecting physical health by spending too much time } \\
\text { on social networking sites }\end{array}$ & 2.92 & 1.03 & 56 & 33.7 & 61 & 36.7 & 47 & 28.3 & 2.31 & 1.08 & 95 & 57.2 & 44 & 26.5 & 24 & 14.4 \\
\hline Becoming addicted to using social networking sites & 3.29 & 1.03 & 38 & 22.9 & 55 & 33.1 & 71 & 42.7 & 2.62 & 1.21 & 77 & 46.4 & 45 & 27.1 & 42 & 25.3 \\
\hline $\begin{array}{l}\text { Spending less time on work, learning or personal } \\
\text { development }\end{array}$ & 3.27 & 1.00 & 31 & 18.7 & 70 & 42.2 & 63 & 37.9 & 2.72 & 1.17 & 66 & 39.8 & 53 & 31.9 & 44 & 26.5 \\
\hline Become involved in bullying others & 2.40 & 0.97 & 98 & 59.1 & 44 & 26.5 & 22 & 13.2 & 1.79 & 0.98 & 132 & 79.5 & 22 & 13.3 & 10 & 6.0 \\
\hline Spending less time with family & 2.87 & 0.97 & 55 & 33.1 & 68 & 41.0 & 41 & 24.7 & 2.44 & 1.17 & 91 & 54.8 & 41 & 24.7 & 31 & 18.7 \\
\hline $\begin{array}{l}\text { Being exposed to inappropriate or offensive violent or } \\
\text { gory content }\end{array}$ & 3.20 & 1.01 & 37 & 22.3 & 71 & 42.8 & 55 & 33.1 & 2.55 & 1.18 & 73 & 50.0 & 51 & 30.7 & 30 & 18.0 \\
\hline Being susceptible to online marketing scams & 3.66 & 1.03 & 20 & 12.0 & 48 & 28.9 & 96 & 57.8 & 2.26 & 1.04 & 110 & 66.3 & 34 & 20.5 & 20 & 12.0 \\
\hline Being stalked & 2.95 & 1.05 & 60 & 36.1 & 54 & 32.5 & 49 & 29.5 & 2.44 & 0.93 & 88 & 53.1 & 62 & 37.3 & 13 & 7.8 \\
\hline Developing or writing harmful online content & 2.65 & 0.94 & 74 & 44.5 & 66 & 39.8 & 24 & 14.4 & 1.88 & 0.99 & 123 & 74.1 & 32 & 19.3 & 9 & 5.4 \\
\hline Being 'groomed' for sexual exploitation or abuse & 3.46 & 1.01 & 25 & 15.0 & 57 & 34.3 & 82 & 49.4 & 1.92 & 1.03 & 121 & 72.9 & 29 & 17.5 & 13 & 7.8 \\
\hline Becoming involved in using online gambling sites & 3.00 & 1.09 & 58 & 34.9 & 56 & 33.7 & 50 & 29.3 & 1.96 & 1.05 & 119 & 71.7 & 31 & 18.7 & 14 & 8.4 \\
\hline $\begin{array}{l}\text { Engaging in copyright infringement and illegal } \\
\text { downloading }\end{array}$ & 3.09 & 1.13 & 49 & 29.5 & 59 & 35.5 & 56 & 33.8 & 2.52 & 1.22 & 91 & 54.8 & 37 & 22.3 & 36 & 21.7 \\
\hline Having their personal data misused by other people & 3.54 & 0.93 & 15 & 9.0 & 68 & 41.0 & 81 & 48.8 & 2.64 & 1.03 & 83 & 44.0 & 62 & 37.3 & 29 & 17.5 \\
\hline Having their accounts hacked & 3.47 & 0.94 & 25 & 15.1 & 55 & 33.1 & 84 & 50.7 & 2.82 & 0.98 & 56 & 33.7 & 76 & 45.8 & 32 & 19.3 \\
\hline $\begin{array}{l}\text { Inadvertently downloading spyware or malware (e.g. } \\
\text { viruses) onto their computer }\end{array}$ & 3.57 & 0.98 & 19 & 12.6 & 54 & 32.5 & 89 & 53.6 & 2.68 & 0.99 & 72 & 43.3 & 59 & 35.5 & 33 & 19.9 \\
\hline
\end{tabular}

viruses) onto their computer

Note 1: For individual risks paired sample t-test comparisons all significant at $p<0.001$ with greater risk perceived for people with LD in all instances.

Note 2: Missing values ranged between 2 and 3 for all risk items.

Note 3: The five online risks considered most and least likely for the two groups are highlighted in bold. 
Table 3: Showing the mean benefit ratings for online opportunities for people with LD and participants and the proportion of participants rating the benefits as low, moderate or high for the two groups

\begin{tabular}{|c|c|c|c|c|c|c|c|c|c|c|c|c|c|c|c|c|}
\hline \multirow{3}{*}{ Benefits } & \multicolumn{8}{|c|}{ People with Intellectual Disabilities } & \multicolumn{8}{|c|}{ Personal Ratings (People without ID) } \\
\hline & \multirow[t]{2}{*}{$\mathbf{M}$} & \multirow[t]{2}{*}{ SD } & \multicolumn{2}{|r|}{ Low } & \multicolumn{2}{|c|}{ Mod. } & \multicolumn{2}{|c|}{ High } & \multirow[t]{2}{*}{$\mathbf{M}$} & \multirow[t]{2}{*}{ SD } & \multicolumn{2}{|r|}{ Low } & \multicolumn{2}{|c|}{ Mod. } & \multicolumn{2}{|r|}{ High } \\
\hline & & & $\mathrm{N}$ & $\%$ & $\mathrm{~N}$ & $\%$ & $\mathrm{~N}$ & $\%$ & & & $\mathrm{~N}$ & $\%$ & $\mathrm{~N}$ & $\%$ & $\mathrm{~N}$ & $\%$ \\
\hline Keeping in contact with friends and family & 4.01 & 0.84 & 4 & 2.4 & 38 & 22.9 & 122 & 73.5 & 3.88 & 1.07 & 15 & 9.0 & 35 & 21.1 & 114 & 68.6 \\
\hline Helps to widen their circle of friends ${ }^{\star \star \star}$ & 3.79 & 0.90 & 13 & 7.8 & 42 & 25.3 & 109 & 65.7 & 3.34 & 1.08 & 32 & 19.3 & 58 & 34.9 & 74 & 44.6 \\
\hline Helps to develop technological skills*** & 3.84 & 0.93 & 13 & 7.8 & 41 & 24.7 & 110 & 66.3 & 3.52 & 1.04 & 26 & 15.7 & 57 & 34.3 & 81 & 48.8 \\
\hline $\begin{array}{l}\text { People can say things they would find uncomfortable } \\
\text { saying face to face }\end{array}$ & 3.37 & 1.13 & 38 & 22.9 & 43 & 25.9 & 83 & 50.0 & 3.01 & 1.16 & 51 & 30.7 & 57 & 34.3 & 56 & 33.7 \\
\hline Share advice with friends & 3.65 & 0.90 & 15 & 9.0 & 53 & 31.9 & 96 & 57.9 & 3.53 & 0.94 & 19 & 12.4 & 56 & 33.7 & 89 & 53.7 \\
\hline Can help to support friends & 3.74 & 0.91 & 13 & 7.8 & 49 & 29.5 & 102 & 61.5 & 3.65 & 0.99 & 16 & 9.6 & 50 & 30.1 & 98 & 59.1 \\
\hline Helps to develop perspective taking skills ${ }^{* *}$ & 3.37 & 1.01 & 30 & 18.1 & 59 & 35.5 & 75 & 45.2 & 3.03 & 1.01 & 42 & 25.3 & 80 & 48.2 & 42 & 25.3 \\
\hline Helps to develop social skills*** & 3.57 & 1.06 & 28 & 16.9 & 41 & 24.7 & 95 & 57.3 & 2.97 & 1.14 & 56 & 33.7 & 58 & 34.9 & 50 & 30.1 \\
\hline Can learn about other cultures & 3.59 & 0.93 & 19 & 11.4 & 58 & 34.9 & 87 & 52.4 & 3.54 & 0.99 & 28 & 16.9 & 47 & 28.3 & 88 & 53.0 \\
\hline Helps to develop decision making skills ${ }^{\star * \star}$ & 3.22 & 1.05 & 42 & 25.3 & 57 & 34.3 & 65 & 39.1 & 2.88 & 1.07 & 64 & 38.5 & 60 & 36.1 & 40 & 24.1 \\
\hline Can learn about wider society** & 3.56 & 0.94 & 22 & 13.2 & 49 & 29.5 & 93 & 56.1 & 3.36 & 0.99 & 33 & 19.9 & 55 & 33.1 & 74 & 44.6 \\
\hline Helps to develop a sense of who they are ${ }^{\star \star \star}$ & 3.29 & 1.11 & 38 & 22.9 & 53 & 31.9 & 72 & 43.4 & 2.77 & 1.15 & 72 & 43.4 & 50 & 30.1 & 41 & 24.7 \\
\hline $\begin{array}{l}\text { They can ask other people for help with their work, } \\
\text { projects or hobbies }\end{array}$ & 3.76 & 0.90 & 13 & 7.8 & 43 & 25.9 & 108 & 65.1 & 3.40 & 0.98 & 27 & 16.3 & 59 & 35.5 & 78 & 46.9 \\
\hline Helps to develop critical thinking skills* & 3.18 & 1.06 & 38 & 22.9 & 68 & 41.0 & 58 & 34.9 & 3.01 & 1.07 & 49 & 29.5 & 69 & 41.6 & 46 & 27.7 \\
\hline Become closer to friends ${ }^{\star * *}$ & 3.64 & 1.05 & 21 & 13.2 & 36 & 21.7 & 105 & 63.3 & 3.21 & 1.11 & 42 & 25.3 & 46 & 27.7 & 75 & 45.1 \\
\hline $\begin{array}{l}\text { Helps to develop literacy skills (e.g. reading and } \\
\text { writing)*** }\end{array}$ & 3.72 & 1.00 & 20 & 12.0 & 38 & 22.9 & 105 & 63.3 & 3.02 & 1.20 & 57 & 34.3 & 47 & 28.3 & 59 & 35.5 \\
\hline $\begin{array}{l}\text { Helps to develop comprehension and understanding } \\
\text { of new information }{ }^{\star * *}\end{array}$ & 3.55 & 0.92 & 22 & 13.2 & 50 & 30.1 & 91 & 54.9 & 3.26 & 1.02 & 38 & 22.9 & 55 & 33.1 & 70 & 42.1 \\
\hline Can learn about work opportunities & 3.74 & 0.97 & 15 & 9.0 & 45 & 27.1 & 103 & 62.1 & 3.75 & 1.04 & 16 & 9.6 & 44 & 26.5 & 103 & 62.1 \\
\hline $\begin{array}{l}\text { Can learn about further educational and work } \\
\text { opportunities (e.g. college courses) }\end{array}$ & 3.91 & 0.97 & 15 & 9.0 & 28 & 16.9 & 120 & 72.3 & 3.84 & 0.96 & 17 & 10.2 & 35 & 21.1 & 109 & 65.7 \\
\hline Give opportunities to participate in social groups ${ }^{* * *}$ & 3.80 & 0.90 & 15 & 9.0 & 34 & 20.5 & 114 & 68.7 & 3.33 & 1.06 & 34 & 20.5 & 54 & 32.5 & 75 & 45.2 \\
\hline Helps to maintain friendships ${ }^{\star * \star}$ & 3.83 & 0.89 & 12 & 7.2 & 39 & 23.5 & 112 & 67.5 & 3.53 & 1.01 & 12 & 11.4 & 62 & 37.3 & 82 & 49.4 \\
\hline Give opportunities to participate in support groups ${ }^{\star \star *}$ & 3.93 & 0.89 & 11 & 6.6 & 35 & 21.1 & 117 & 70.5 & 3.06 & 1.14 & 52 & 31.3 & 52 & 31.3 & 59 & 35.5 \\
\hline $\begin{array}{l}\text { Give opportunities to participate in advocacy } \\
\text { groups }{ }^{\star \star \star}\end{array}$ & 3.41 & 0.93 & 25 & 15.1 & 67 & 40.4 & 72 & 43.4 & 2.84 & 1.04 & 56 & 33.7 & 71 & 42.8 & 37 & 22.3 \\
\hline Can share information about their lives with others ${ }^{\star \star \star}$ & 3.38 & 0.97 & 29 & 17.5 & 60 & 36.1 & 75 & 45.1 & 2.82 & 1.11 & 62 & 37.3 & 62 & 37.3 & 39 & 23.5 \\
\hline Learn about and be inspired to try new things ${ }^{\star \star *}$ & 3.48 & 0.93 & 7 & 4.2 & 53 & 31.9 & 104 & 62.7 & 3.82 & 0.95 & 22 & 13.2 & 57 & 34.3 & 85 & 61.2 \\
\hline $\begin{array}{l}\text { Increase understanding about their human rights and } \\
\text { entitlements }\end{array}$ & 3.82 & 0.95 & 13 & 7.8 & 44 & 26.5 & 107 & 64.5 & 3.37 & 1.03 & 33 & 19.9 & 51 & 30.7 & 80 & 48.1 \\
\hline $\begin{array}{l}\text { Access and use advice sites (e.g. benefits, health, } \\
\text { relationships) }\end{array}$ & 3.87 & 0.91 & 16 & 9.6 & 31 & 18.7 & 117 & 70.5 & 3.41 & 1.07 & 32 & 19.3 & 44 & 26.5 & 88 & 53.1 \\
\hline Helps to develop expressive communication skills ${ }^{* * *}$ & 3.67 & 1.00 & 16 & 9.6 & 52 & 31.3 & 96 & 57.8 & 3.09 & 1.13 & 44 & 26.5 & 64 & 38.6 & 56 & 33.7 \\
\hline
\end{tabular}




\section{Discussion}

This paper provides empirical evidence supporting a presumption which exists around ICT use by people with intellectual disabilities, namely that both the benefits and risks of being online are perceived to be greater for people with intellectual disabilities than the neuro-typical majority. That such benefits are perceived to exist for people with intellectual disabilities provides indirect evidence that people are pro-inclusion, in line with Scior (2011), but in relation to the online world. However, the findings also lend support to the idea that people view those with intellectual disabilities as having different problems to themselves (Eggert \& Berry, 1992), though not for all online benefits and risks.

There seemed to be some misconceptions and misunderstandings of the accessibility of some online activities which may make them extremely challenging for people with intellectual disabilities without extensive support and hence would be unlikely to present a risk to people with intellectual disabilities when online (e.g. being susceptible to online marketing scams). This suggests a lack of awareness of the support that people may require to access online activities and content. Though these risks were not viewed as particularly great for people with intellectual disabilities and may be greater in none disabled people, without comparative research such assumptions may remain.

Being able to try out decision making skills was viewed as one of the least beneficial aspects of being online for people with intellectual disabilities. This may indeed reflect that these opportunities were not viewed as beneficial or, alternatively, that participants may not have been able to see how being online could provide a forum whereby people with intellectual disabilities could try out and test decision making in a self-directed way, which may not be quite as readily available to people with intellectual disabilities in the offline world. Opportunities for engaging in and testing out decision making online for people with intellectual disabilities and those providing support for them warrants further exploration (Seale, 2014), as the literature suggests this group are often afforded fewer opportunities for decision making (Stalker \& Harris, 1998).

Consensus around the actual risks inherent in some of the online risks in the survey remains contentious and debated (e.g. exposure to pornographic material) (e.g. Harkness et al., 2015; Ludder et al., 2011). The finding of perceived higher online vulnerability prompts consideration of the equality of treatment of young people and adults with intellectual disabilities with regard to Internet use. It may underpin the 'digital divide' that has been found for people with intellectual disabilities (Chadwick \& Wesson, 2016). It also reinforces the tension that exists around exerting power to protect people who are viewed as more vulnerable, whilst at the same time supporting people to make decisions about their lives and avoiding restriction of their personal liberty. Future research to investigate the views gatekeepers hold over such 
risks and their behavioural responses to people with intellectual disabilities wanting to engage in arguably more risky behavior in the online world requires study.

Increased awareness of the society stigma that people with intellectual disabilities often experience may underpin rating people with intellectual disabilities as more at risk of being bullied, threatened or harassed online. The resilience and impact of experiencing online risks amongst people with intellectual disabilities has been considered in the research literature (Seale et al., 2012; Seale, 2014) but remains relatively unexplored and is an area in need of further investigation. This finding also indicates that the non-disabled participants in this study appear to have worries and concerns akin to some of those reported by caregivers in previous research (Löfgren-Mårtenson, 2008). Furthermore, although the responses to the survey within the present study focused on the likelihood of risks occurring, risk models often also incorporate an indication of risk severity in terms of subsequent repercussions. This could usefully be considered in future risk as not all online risks may be viewed as equivalent in severity by people with intellectual disabilities, their supporters or wider society. Gauging perceptions and management of risk from people with intellectual disabilities and those providing everyday support could also inform support practices and interventions.

The view that people with intellectual disabilities are more vulnerable and at greater risk online may be underpinned by the preconception that people with intellectual disabilities have reduced coping skills or to doubts people have regarding the ability people with intellectual disabilities have in coping with adverse online experiences (Goodley, 2005; Dagnan, 2008). Beliefs that people with intellectual disabilities are less able to successfully identify or recognise risky online situations, particularly ones where some form of subterfuge is involved (e.g. scams) may also underpin risk ratings. This fits with a more deficit model perspective indicating that, as with general attitudes to people with intellectual disabilities (Blundell et al., 2016; Scior, 2011) more research and practice work needs to be done to reduce misconceptions and counteract prejudicial assumptions of reduced ability and the need for child like protection online for people with intellectual disabilities (Pueschel \& Scola, 1988). A deficit model does not best serve people here, rather a model focusing on building skills, awareness and resilience around risks, guidance on online positive risk taking and how to best support access to beneficial aspects of the online world is, we argue, a better way forward towards promoting access to the online world for people with an intellectual disabilities (Seale et al., 2012; Seale, 2014). Empirical study considering online resilience and coping with potentially adverse events online amongst people with intellectual disabilities and how best to support and develop risk management skills is also needed. That participants perceived themselves to be less vulnerable to risk may also be explained with reference to the illusory superiority bias (above average effect). This cognitive bias has been demonstrated in a number of areas and suggests that people have a tendency to consistently over-estimate their own abilities and intelligence comparative to others (Hoorens \& Bunk, 1992). 
Although the aim of this study was to investigate beliefs about the relative risks and benefits of being online we still do not know if the online risks and benefits perceived to be higher here actually translate into actual risks and benefits when people with intellectual disabilities are online. This is a question that could usefully be answered in future research. Additionally, although background information was gathered from participants in the study, this did not allow us to gauge the representativeness of the sample. Our aim was to gain some insight into perceptions of the general population and we were unable to demonstrate that our sample represented this population to a high degree, particularly geographically. In addition, although we wanted a range of views, many participants were university students, another indication that our results may not reflect those of the general population. Replication and extension of this work cross-culturally and with a wider cross section of age and circumstance is indicated.

It was surprising that regularity of contact was not found to relate to perceptions of risk and benefit likelihood, given prior research findings that attitudes towards disability may be altered through increased contact (Blundell et al., 2016). However we are limited in the interpretations we can make by the data gathered because it did not address the quality of contact or whether contact involved any consideration of being online. A more nuanced approach to contact including frequency, closeness and nature of contact may better explain attitudes towards being online for people with intellectual disabilities, which is supported in the literature around predictors of general attitudes to those with intellectual disabilities (Blundell et al., 2016). More research is needed to explore attitudes to being online and how contact and other variables may relate to beliefs about online risks and benefits.

As the benefits of being online are viewed as greater for people with intellectual disabilities, this raises the question - Why then is more not done to support people to get online and to use the Internet more effectively towards accruing some of these benefits? To enable more safe and frequent opportunities for being online a number of strategies could be developed, implemented and evaluated: (i) support and training for people with intellectual disabilities to support the development of their skills in using the Internet and other ICT and getting online; (ii) training of those who could facilitate people with intellectual disabilities to get online to better be able to do this kind of support, e.g. paid and family carers; (iii) additional training around management of online risk; and (iv) gauging the views and experiences of people with intellectual disabilities and those who support them to inform and facilitate implementation of 'universal design'. Some of these strategies have been introduced in some places (e.g. Williams, 2006; Williams, 2011), but further work of this nature is warranted. Such user led work is likely to improve the accessibility of the online world to people with intellectual disabilities and reduce the 'digital divide'.

\section{Conclusions}

With a few exceptions people perceived both greater risk and greater benefits to being online for people with intellectual disabilities than for themselves. 
Belief in the benefits of being online related to the range and frequency of personal online engagement. Increased benefit of being online suggests the need for research and training to enhance opportunities to get online and evaluation of online benefits for people with intellectual disabilities. The perceived increased risks helps to explain the increased restriction and gatekeeping that may occur preventing people from getting online and the tension that exists in protecting people from risks and affording people selfdetermination and liberty in the online world. There is a need for future work to support identification of protective factors so as to prevent the online world being one more space in which people intellectual disabilities are excluded. 


\section{References}

Adger, W. N. (2006). Vulnerability. Global Environmental Change, 16, 268281.

Alaszewski, A. \& Alaszewski, H. (2002). Towards the Creative Management of Risk: Perceptions, Practices and Policies. British Journal of Learning Disabilities, 30, 56-62.

Bannon, S., McGlynn, T. \& Quayle, E. (2015). The positive role of Internet use for young people with additional support needs: Identity and connectedness. Computers in Human Behaviour, 53, 504-514.

Blundell, R., Das, R., Potts, H., Scior, K. (2016). The association between contact and intellectual disability literacy, causal attributions and stigma. Journal of Intellectual Disability Research, 60(3), 218-227.

Buijs, P. C. M., Boot, E., Shugar, A., Fung, W. L. A. and Bassett, A. S. (2016), Internet Safety Issues for Adolescents and Adults with Intellectual Disabilities. Journal of Applied Research in Intellectual Disabilities. doi: 10.1111/jar.12250 Chadwick, D., Fullwood, C., \& Wesson, C. (2012). Intellectual disability, identity and the Internet. In R. Luppicini (Ed.) Handbook of research on technoself: identity in a technological society, 229-254. Canada IGI Global. [DOI: 10.4018/978-1-4666-2211-1, ISBN13: 9781466622111] Chadwick, D. D. \& Wesson, C. (2016). Digital Inclusion \& Disability. In: Attrill. A. \& Fullwood C. Applied Cyberpsychology: Applications of cyberpsychological theory and research, Publisher: Palgrave Macmillan, pp.124.

Chadwick, D., Wesson, C., \& Fullwood, C. (2013). Internet access by people with intellectual disabilities: Inequalities and opportunities. Future Internet, 5(3), 376-397.

Dagnan, D. (2008). Psychological and Emotional health and well-being of people with Intellectual Disabilities. Learning Disability Review, 13(1), 3-9. Eggert, D., \& Berry, P. (1992). German, Irish and Australian high school students' perceptions of mental handicap. International Journal of Rehabilitation Research, 15, 349-354.

Feng, J., Lazar, J., Kumin, L. Ozok, A. (2008). Computer Usage by Young Individuals with Down Syndrome: An Exploratory Study. In Proceedings of Assets '08 Proceedings of the 10th International ACM SIGACCESS

Conference on Computers and Accessibility, Nova Scotia, Canada, 13-15 October 2008; 35-42.

Goodley, D. (2005). Empowerment, self advocacy and resilience. Journal of Intellectual Disabilities, 9, 333-343.

Harkness, E.L., Mullan, B.M. \& Baszczynski, A. (2015). Association Between Pornography Use and Sexual Risk Behaviors in Adult Consumers: A

Systematic Review Cyberpsychology, behavior and social networking, 18(2), $1-13$.

Hoorens, V., \& Buunk, A.P. (1992). Self-serving biases in social comparison: Illusory superiority and unrealistic optimism. Psycholigica Belgica, 32(2), 169194.

Hoppestad, B. S. (2013). Current perspective regarding adults with intellectual and developmental disabilities accessing computer technology. Disability and Rehabilitation.Assistive Technology, 8(3), 190. 
Lathouwers, K., de Moor, J, \& Didden, R. (2009). Access to and use of Internet by adolescents who have a physical disability: A comparative study. Research in Developmental Disabilities, 30, 702-711.

Livingston, S. \& Haddon, L. (2009). EU Kids Online Final report. LSE, London: EU Kids Online. (EC Safer Internet Plus Programme Deliverable D6.5) Lofgren-Martenson, L. (2008). Love in cyberspace: Swedish young people with intellectual disabilities and the Internet. Scandinavian Journal of Disability Research, 10, 125-138.

Luder, M.T., Pittet, I., Berchtold, A., Akre, C. Michaud, P. A. \& Suris, J.C. (2011). Associations between online pornography and sexual behavior among adolescents: myth or reality? Archives of Sexual Behaviour, 40, 1027-1035.

Morgan, S. (2004). Positive Risk Taking: An Idea Whose Time Has Come. Health Care Risk Report, 10(10), 18-19.

Näslund, R. \& Gardelli, A (2013). 'I know, I can, I will try': youths and adults with intellectual disabilities in Sweden using information and communication technology in their everyday life. Disability and Society, 28(1), 28-40.

Palmer, S.B., Wehmeyer, M.L., Davies, D.K. \& Stock, S.E. (2012). Family members' reports of the technology use of family members with intellectual and developmental disabilities. Journal of Intellectual Disability Research, 56, 402-414.

Peacock, S. E. and Künemund, K. (2007). Senior Citizens and Internet Technology. European Journal of Ageing, 4(4). Springer-Verlag: 191-200. Porter, C.E. \& Donthu, N. (2006). Using the technology acceptance model to explain how attitudes determine Internet usage: The role of perceived access barriers and demographics. Journal of Business Research, 59, 999-1007. Pueschel, S. M., \& Scola, P. S. (1988). Parents' perception of social and sexual functions in adolescents with down's syndrome. Journal of Mental Deficiency Research, 32(3), 215.

Reyna, V.F. \& Rivers, S.E. Current theories of risk and rational decision making. Developmental review, 28(1), 1-11.

Scior, K. (2011). Public awareness, attitudes and beliefs regarding intellectual disability: A systematic review. Research in Developmental Disabilities, 32, $2164-2182$.

Seale, J. K. (2001). The Same but Different: The Use of the Personal Home Page by Adults with Down Syndrome as a Tool for Self-presentation. British Journal of Educational Technology, 32(3), 343-352.

Seale, J. (2003). Researching home page authorship of adults with learning disabilities: Issues and dilemmas. Proceedings of International Education Research Conference AARE - NZARE, Auckland, New Zealand, 30 Nov - 3 Dec 2003.

Seale, J., M. Nind, and B. Simmons. (2012). Transforming Positive Risk Taking Practices: The Possibilities of Creativity and Resilience in Learning Disability Contexts. Scandinavian Journal of Disability Research, 15(3), 233248. http://www.tandfonline.com/doi/ abs/10.1080/15017419.2012.703967 Seale, J. (2014). The Role Of Supporters In Facilitating Use Of Technologies By Adolescents And Adults With Learning Disabilities: A Place For Positive Risk Taking? European Journal of Special Needs Education, 29(2), 220- 236 Seale, J. K. (2007). Strategies for supporting the online publishing activities of adults with learning difficulties. Disability \& Society, 22(2), 173-186. 
Shpigelman, C \& Gill, C. J. (2014). Facebook use by persons with disabilities. Journal of Computer-mediated Communication, 19, 610-624

Stalker, K. \& Harris, P. (1998) The exercise of choice by adults with

intellectual disabilities: A literature review. Journal of Applied Research in Intellectual Disabilities, 11(1), 60-76.

Stendal, K. (2012). How do people with disability use and experience virtual worlds and ICT: A Literature Review. Journal of Virtual Worlds Research, 5(1), 1-17.

Stendal, K., Balandin, S. \& Molka-Danielson, J. (2011). Virtual worlds: A new opportunity for people with lifelong disability. Journal of Intellectual and Developmental Disability, 36(1), 80- 83.

Thurlow, C.(2006). From statistical panic to moral panic: The metadiscursive construction and popular exaggeration of new media language in the print media. Journal of Computer Mediated Communication, 11(3), 667-701. Williams, P. (2006). Developing Methods to Evaluate Web Usability with People with Learning Difficulties. British Journal of Special Education, 33(4): 173-179.

Williams, P. (2011). Barriers to the Creation and Use of an Accessible Web Portal for People with Learning Disabilities. International Journal of Education, 3(2), E21.

Zinn, J. O. (2006). Recent developments in sociology of risk and uncertainty. Forum: Qualitative social research, 7(1), Art 30. 